\title{
MORFología Y ULTRAESTRUCTURA DE LAS ESPORAS DE LAS Equisetaceae (Equisetopsida) del Noroeste de Argentina
}

\author{
MARÍA RAQUEL PIÑEIRO'1 y MARTA A. MORBELLI
}

\begin{abstract}
Resumen: La familia Equisetaceae se haya representada en el Noroeste de Argentina por el género Equisetum Michx. ex DC con dos especies, E. bogotense Kunth y E. giganteum L. El estudio se realizó en base a material de herbario y fresco. Las observaciones se realizaron con microscopios óptico y electrónicos de barrido y transmisión. Las esporas son esferoidales, miden 35-64 um de diámetro ecuatorial, su citoplasma posee clorofila. En ambas especies, las esporas presentan una estructura abertural circular y a ambos lados de la misma poseen un par de eláteres acintados de extremos espatulados, no resistentes al tratamiento de acetólisis. La esporodermis consta de dos paredes, perisporio, delgado, ornamentado, con dos estratos, de $930 \mathrm{~nm}-1,2 \mu \mathrm{m}$ de espesor, y exosporio, de 1,4$3,1 \mu \mathrm{m}$ de espesor, compacto, con dos estratos y superficie levemente ondulada o plegada. Entre ambas paredes se ha observado una capa intermedia de naturaleza laxa, y diferente espesor en esporas con distintos estadios de maduración. Las esporas son similares, en ambas especies, en cuanto a la forma y ultraestructura de la esporodermis; se observan diferencias en el tamaño de las mismas.
\end{abstract}

Palabras clave: Equisetaceae, Equisetum, Argentina, esporas, morfología, ultraestructura.

Summary: Spore morphology and wall ultrastructure in Equisetaceae spores (Equisetopsida) from north-western Argentina. The family Equisetaceae is represented in the study area by the genus Equisetum with two species, E. bogotense and E. giganteum. The study was based on herbarium and fresh specimens and the spores were studied under light microscope, scanning and transmission electron microscopes. The spores are spheroid, 35-64 $\mu \mathrm{m}$ in equatorial diameter, the cytoplasm has chlorophyll. In both species studied, the spores have a circular and small unique type of aperture which at both sides of the aperture, in the outer side have two thread-like elaters, spathulate. These structures are non-resistant to the acetolysis treatment. The sporoderm is composed of two walls, perispore, 930 $\mathrm{nm}-1,2 \mu \mathrm{m}$ thick, ornamented, with two layers in section. The exospore is two layered, compact, 1,4-3,1 $\mu \mathrm{m}$ thick, slightly wave-like. Between both walls was observed an intermediate layer composed of a laxe structure, in spores in different stages of maturation. In both species, the spores are similar in the shape and sporoderm ultrastructure while differences were found in spore sizes.

Key words: Equisetaceae, Equisetum, Argentina, spores, morphology, ultrastructure.

\section{INTRODUCCIÓN}

El presente estudio tiene como objetivo sumar a la Flora Palinológica del Noroeste argentino (ver detalle en Gardenal et al., 2007) el tratamiento palinológico de una de las 23 familias citadas para la región, las Equisetaceae. Se trata de una familia muy antigua y estable desde el punto de vista evolutivo. En la actualidad se haya representada por

${ }^{1}$ Cátedra de Palinología, Facultad de Ciencias Naturales y Museo, Universidad Nacional de La Plata, La Plata, Argentina. un único género relictual, Equisetum, que data del Carbonífero Superior (Tryon \& Lugardon, 1991). Se trata de un taxón con escasos registros fósiles y semifósiles (Large \& Braggings, 1991).

El género Equisetum, se haya representado por aproximadamente 25 especies, con una amplia distribución en todos los continentes, excepto en gran parte de Oceanía (Australia y Nueva Zelanda). En Argentina sólo crecen dos especies: Equisetum bogotense y E. giganteum (Ponce \& de la Sota, 2008), ambas presentes en hábitats orófilos. E. bogotense crece sobre paredones húmedos, a orillas de ríos y arroyos y habita desde América Central y Grandes Antillas, hasta Bolivia y Chile. 
En Argentina se la encuentra principalmente en la región de Cuyo y en los bosques andino-patagónicos. E. giganteum en cambio, tiene una distribución que abarca América tropical, desde el Sur de México y Haití hasta Chile, Uruguay y Noroeste argentino (de la Sota, 1977). Se ha observado en la actualidad, que estas especies tienen uso ornamental.

Varios autores han estudiado las esporas de Equisetum con microscopía óptica y electrónica, de barrido y transmisión. Durante mucho tiempo las esporas fueron consideradas inaberturadas o criptoaberturadas. Recién en 1954 Erdtman, y más tarde Erdtman \& Sorsa (1971), describieron en ellas una abertura de tipo transicional, entre alete y monolete.

En Argentina Morbelli (1980), ha descripto para las esporas acetolizadas de E. bogotense con distribución en la región Fuego-patagónica, una "zona circular diferenciada".

Ferrarini et al. (1986) analizaron las esporas de varias especies de Equisetum para la región mediterránea y, las describieron también como aletes, de superficie escabrada a granulada, y provistas de amplessorios (= eláteres) espatulados. Los eláteres en sección, fueron estudiados por Lugardon (1969), en esporas de Equisetum maximum Lamk. de los alrededores de Toulouse, Francia, refiriéndose a la naturaleza celulósica, y a la superficie de los mismos, con abundantes cuerpos globulares; en la esporodermis, menciona 2 paredes perisporio y exosporio y una tercera capa entre ambas paredes, constituida por una sustancia finamente granular, de contorno delimitado.

Tryon \& Tryon (1982), han empleado el término episporio para referirse a la pared externa de estas esporas, en lugar de perisporio. Se ha observado que varios autores utilizan indistintamente estos vocablos, pero recientes estudios aportados por Rincón Barón et al. (2011), han establecido coincidencias sobre el origen del perisporio y episporio, por lo que sugieren emplear cualquiera de ambos términos para referirse a las paredes de estas esporas.

Se han consultado los estudios realizados con MET en esporas de Equisetum bogotense y E. giganteum por Tryon \& Lugardon (1991), quienes se refieren a la esporodermis en sección constituida por dos paredes, episporio y exosporio, y a la característica coloración verdosa que presentan estas esporas.
Kurmann \& Taylor (1984) han realizado un estudio comparativo entre las esporas fósiles de Elaterites y las actuales de Equisetum encontrando a nivel de la ultraestructura, características similares en ambas.

\section{Materiales y Métodos}

El estudio palinológico se realizó en base a material de herbario de la División Plantas Vasculares, Museo de Ciencias Naturales de La Plata, Universidad Nacional de La Plata (LP):

Equisetum bogotense. ARGENTINA. Prov. Jujuy:

Dpto. Capital, Cabrera 15885 (LP), MP 4150;

Prov. Salta: Dpto. Capital, Cabrera 2944 (LP), MP 4149.

Equisetum giganteum. ARGENTINA. Prov. Jujuy:

Dpto. Ledesma, Cabrera et al. 23596 (LP), MP

4151; Prov. Salta: Dpto. Santa Victoria, Cabrera \& Kiesling 25141 (LP), MP 4148.

Parte del material fue tratado con $\mathrm{CO}_{3} \mathrm{Na}_{2}$ (3 $\%)$ en caliente y acetolizado (Erdtman, 1960). Para el análisis al MO las esporas se montaron en glicerina-gelatina. Las paredes de las esporas, luego del tratamiento químico se pliegan fácilmente y son escasas las que se conservan turgentes. Las observaciones y mediciones se efectuaron con microscopios ópticos, Olympus CH-2 y BH-2.

Para el estudio con microscopio electrónico de barrido (MEB) las esporas fueron montadas sobre cinta bifaz, sin tratamiento previo y posteriormente metalizadas con oro-paladio. Las observaciones se realizaron con un microscopio JEOL, JSMT-100.

Para el estudio con microscopio electrónico de transmisión (MET), se utilizó material fresco y de herbario. El material fue hidratado, según la técnica propuesta por Rowley \& Nilsson (1972) con solución de alcian blue (AB) en buffer de fosfato al $1 \%$, y fijado en glutaraldehido más solución de alcian blue al $1 \%$ en buffer de fosfato, durante 12 horas. La post-fijación se realizó con tetróxido de osmio al $1 \%$, en solución acuosa más alcian blue al $1 \%$, en buffer de fosfato durante una hora y lavados tres veces en buffer de fosfato más alcian blue. Posteriormente, las esporas fueron deshidratadas en series sucesivas de acetona desde 30\% hasta $100 \%$, y luego embebidas en resina Spurr (Spurr, 1969). Las secciones de $3 \mu \mathrm{m}$ de espesor, fueron teñidas con azul de toluidina y observadas con MO. 


\section{R. Piñeiro y M. A. Morbelli - Morfología y ultraestructura de esporas de Equisetaceae}

Los cortes ultrafinos fueron teñidos con acetato de uranilo (1\%) por 15 minutos, y luego con citrato de plomo por 3 minutos. Las observaciones fueron realizadas con un microscopio Zeiss T-109.

Para la descripción de las esporas se ha seguido la terminología empleada por Kremp (1965), Tryon \& Lugardon (1991), Lellinger and Taylor (1997) y Punt et al. (2007).

Los preparados correspondientes a cada ejemplar estudiado, quedan depositados en la Palinoteca de la Cátedra de Palinología de la Facultad de Ciencias Naturales y Museo, bajo los números de muestra palinológica (MP) 4148 al 4151.

\section{Resultados}

Al MO, las esporas de ambas especies se observan esferoidales, miden $35-40 \mu \mathrm{m}$ de diámetro en E. bogotense y 43-67 $\mu \mathrm{m}$, en E. giganteum. Presentan contenido citoplasmático "verdoso", debido a la presencia de clorofila, y constan de dos eláteres acintados con extremos espatulados que se extienden cuando secos, contribuyendo a la dispersión de las esporas. En ambas especies, las esporas presentan una abertura circular, proximal, de $12,8 \mu \mathrm{m}$ de diámetro, que posee un obturador subabertural. Entre el material acetolizado, es común encontrar esporas deformadas, debido a la ausencia de contenido celular y a la deshidratación producida por el tratamiento químico. Las esporas constan de dos paredes: perisporio externo, amarillento, ornamentado, y exosporio interno, castaño y de superficie levemente ondulada.

Al MEB, la superficie del perisporio presenta elementos globulares de diferentes tamaños, distribuidos aleatoriamente. Las esporas sin tratamiento acetolítico, presentan elementos globulares abundantes en E. bogotense y escasos en E. giganteum. Sobre las esporas deshidratadas, es común observar la presencia de pliegues bajos y delgados que delimitan áreas "poliédricas" e irregulares (Fig. 1 E, F, G), las que han sido consideradas como "artefactos". Los eláteres, como han descripto los autores citados, presentan extremos espatulados y se observa claramente en una de las fotos, el enrollamiento helicoidal en torno a la espora (Fig. 1 A, B, C, D).

Al MET, el perisporio mide entre $930 \mathrm{~nm}$ y 1,2 $\mu \mathrm{m}$ de espesor, es ondulado en sección, y consta de dos estratos, uno externo $(\mathrm{Pe})$, de estructura granular, y otro interno $(\mathrm{Pi})$, de estructura laxa. El exosporio mide 1 a $3 \mu \mathrm{m}$ de espesor, tiene estructura compacta, con un margen externo levemente ondulado, es menos contrastado que el perisporio, y también consta de dos estratos, uno externo (Ee) y otro interno (Ei), ambos con diferente contraste y espesor (Fig. 2 A, C, D).

Entre el material estudiado, se han podido observar esporas en distintos estadios de maduración, en los que ha sido posible evidenciar, entre el exosporio y el perisporio, la presencia de fibrillas dispuestas en forma desordenada, que forman una estructura laxa (Fig. 2: A, B, E, F).

\section{Discusión y Conclusiones}

Las esporas de los Equisetum son particulares respecto a la abertura y a la presencia de estructuras anexas, que las diferencian marcadamente del resto de las esporas de los helechos. En lo que respecta al material analizado, la forma de las esporas y las características ultraestructurales de la esporodermis muestran similitud entre las especies estudiadas y son coincidentes con las citas aportadas por los autores, para otras especies del género.

La presencia de clorofila en estas esporas, es una característica que también hemos observado en esporas de otras familias de helechos no afines, como las Hymenophyllaceae (Wagner, 1974; Morbelli et al., 2010) y las Blechnaceae, sólo en algunas especies (Morbelli, 1976).

Entre el material analizado, la presencia de esporas en distintos estadios de maduración ha permitido reconocer, describir y documentar con MET la observación de una capa intermedia (Ci), ubicada entre el exosporio y el perisporio, de estructura laxa y con distintos espesores según la porción de la espora seccionada. Esta sería la capa que Kurmann \& Taylor (1984) mencionan para las esporas fósiles de Elaterites triferens Wilson, y la que Lugardon (1969) describe para las esporas actuales de Equisetum maximun Lamk.

Se pueden establecer diferencias entre las especies estudiadas, en cuanto al tamaño de las esporas; ya que las de E. giganteum presentan diámetros ecuatoriales mayores, llegando a medir en promedio hasta $67 \mu \mathrm{m}$; y las de E. bogotense no 
Bol. Soc. Argent. Bot. 49 (1) 2014
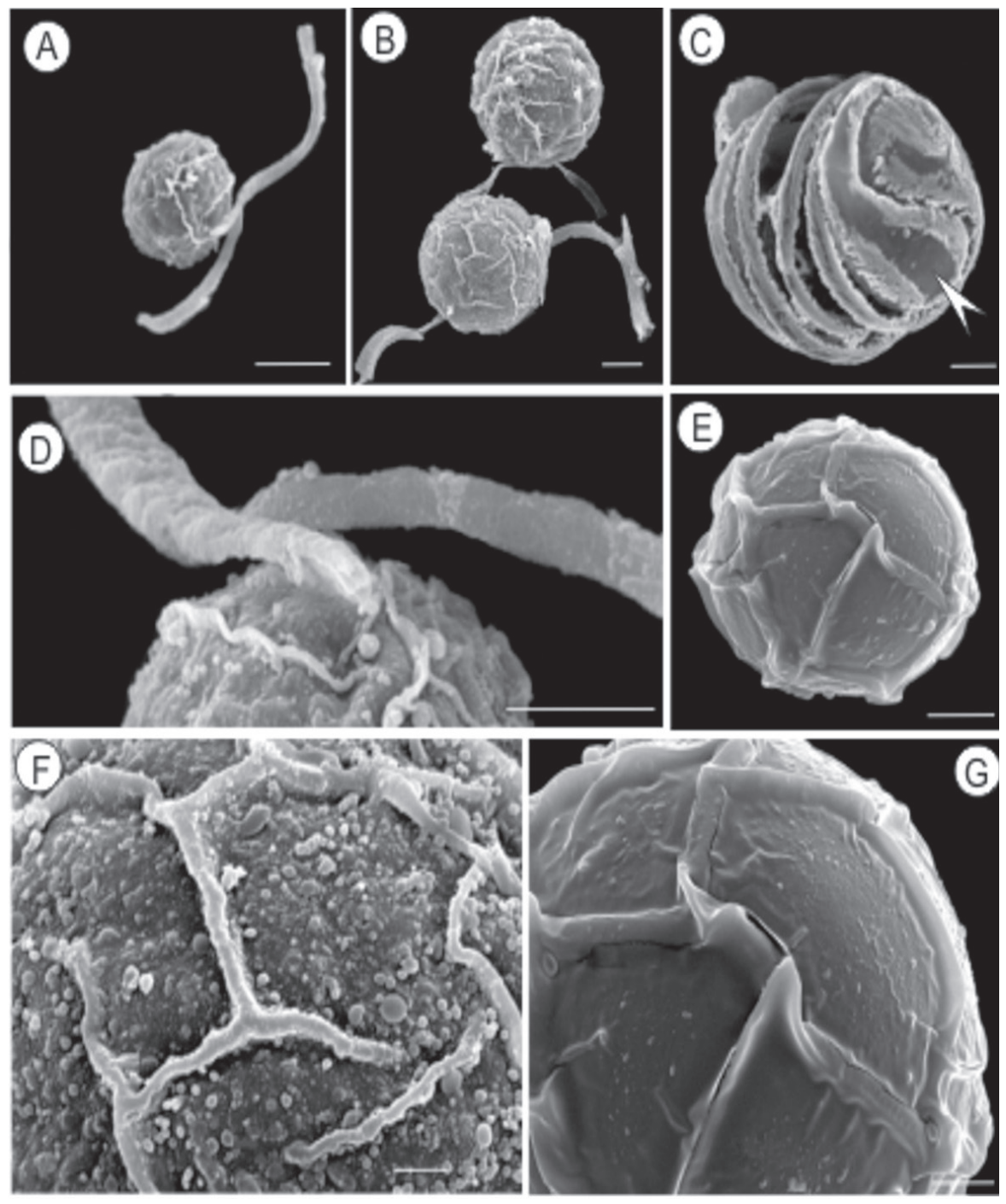

Fig. 1. Esporas de Equisetum con MEB: A, B, D, F. Equisetum bogotense: A, B. Esporas en las que se pueden observar los eláteres desenrollados. (D) Detalle de la zona de inserción de los eláteres. (F) Foto en la que se observa la superficie de la espora deshidratada, obsérvese la delimitación en áreas poliédricas ("artefactos") y la presencia de abundantes glóbulos sobre la superficie. Equisetum giganteum: C, E, G. (C) Espora en la que se visualiza claramente el enrollamiento helicoidal de los eláteres en torno a la espora y la forma terminal espatulada de los mismos (punta de flecha). (E) Espora esferoidal deshidratada en la que se observa sobre su superficie la delimitación de áreas poliédricas ("artefactos"). (G) Vista en detalle de las áreas poliédricas en las que se observa la escasa presencia de glóbulos sobre la superficie de la espora. Escalas: A: $20 \mu \mathrm{m}, \mathrm{B}-\mathrm{E}: 10 \mu \mathrm{m}, \mathrm{F}: 2 \mu \mathrm{m}, \mathrm{G}: 5 \mu \mathrm{m}$.

superan los $36 \mu \mathrm{m}$. También se ha podido observar sobre las paredes, la presencia de glóbulos y esférulas (Tryon \& Lugardon, 1991), abundantes en las esporas de E. bogotense y escasos en las de E. giganteum (Fig. 1 F).

\section{Agradecimientos}

Las autoras desean recordar al querido y recientemente fallecido, Dr. Elías de la Sota, principal referente de este grupo de plantas. Desean, 

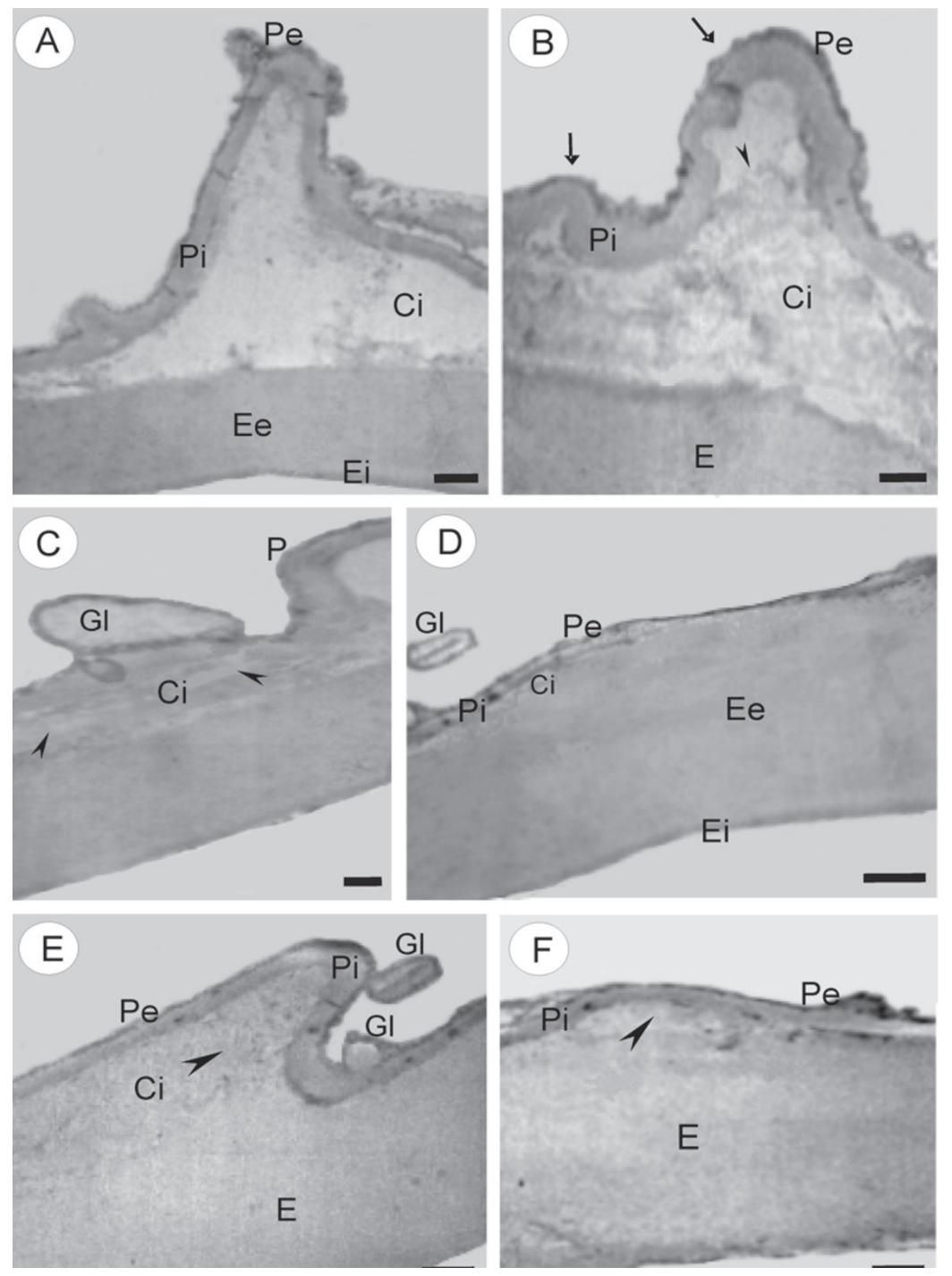

Fig. 2. Secciones de la esporodermis en Equisetum giganteum con MET. (A) Foto en la que se observan las dos paredes, exosporio (E), de margen liso y perisporio $(\mathrm{P})$, con pliegues y glóbulos. La sección corresponde a la zona donde se eleva un pliegue, en la que se observan las dos capas del exosporio, la externa, gruesa y contrastada (Ee) y la interna, delgada y menos contrastada (Ei). Entre el exosporio y perisporio se visualiza la capa intermedia (Ci), de estructura laxa; en la región superior esta capa se rompe quedando restos de la misma. En el perisporio se evidencian los dos estratos, interno $(\mathrm{Pi})$, y externo $(\mathrm{Pe})$, contrastado, de superficie irregular, y con un desarrollo más completo según el sector de la espora. (B) Sección en la que se visualizan dos pliegues de distinta altura (flechas). En la región superior interna del pliegue, se observa la capa intermedia (Ci) fragmentada (cabeza de flecha). (C) Otra sección en la que se observa la capa intermedia (Ci) en otra etapa de maduración, de composición laxa y depositada a modo de estratos paralelos (cabezas de flecha). Sobre el perisporio se observa un glóbulo (Gl) de forma alargada, constituido por dos "paredes" de contraste similar al perisporio y exosporio. (D) Sección de la esporodermis en la que se observan los estratos del perisporio (Pe y $\mathrm{Pi}$ ) y del exosporio (Ee y Ei), la capa intermedia (Ci) y a la izquierda un glóbulo (GI). (E) Pliegue en sección en el que se distinguen dos glóbulos (GI) de distinta forma y tamaño, uno de ellos se ubica sobre el perisporio. Es posible observar además, la estructura laxa de la capa intermedia (cabeza de flecha). (F) Sección de un pliegue bajo, en el que es posible observar sobre su base, una pequeña porción de capa intermedia (cabeza de flecha). Escalas: A, B: 0,2 $\mu \mathrm{m} ; \mathrm{C}-\mathrm{F}: 0,5 \mu \mathrm{m}$. 
además, expresar su agradecimiento al Lic. Rafael Urrejola de la Unidad de Microscopía Electrónica de Barrido, Facultad de Ciencias Naturales y Museo, Universidad Nacional de La Plata. Este trabajo fue financiado con fondos aportados por el Consejo Nacional de Investigaciones Científicas y Técnicas, CONICET (PIP 5044 y 1085), la Agencia Nacional para la Promoción de la Ciencia y Tecnología, ANPCyT (PICT 12758) y la Universidad Nacional de La Plata (Proyectos 451 y 584).

\section{Bibliografía}

ERDTMAN, G. 1960. The acetolysis method. A revised description. Sv. Bot. Tidsskr. 54: 561-564.

ERDTMAN, G. \& P. SORSA. 1971. Pollen and spore morphology/Plant taxonomy. Pteridophyta (Text and additional illustrations). An introduction to Palynology, 4. Almqvist \& Wiksells, Stockholm.

FERRARINI, E., F. CIAMPOLINI, R. PICHI SERMOLLI \& D. MARCHETTI. 1986. Iconographia Palynologica Pteridophytorum Italiae. Webbia 40: 1-202.

GARDENAL, P., M.A. MORBELLI \& G. E. GIUDICE. 2007. Morphology and ultrastructure of heterosporous Filicophyta spores from north-west Argentina. Grana 46: 65-77.

KREMP, G.O.W. 1965. Morphologic Encyclopedia of Palynology. The University of Arizona Press, Tucson.

KURMANN, M. H. \& T. N. TAYLOR. 1984. Comparative ultrastructure of the sphenophyte spores Elaterites and Equisetum. Grana 23: 109-116.

LARGE, M. F. \& J. E. BRAGGINS. 1991. Spore atlas of New Zealand ferns \& fern allies. A Supplement to the New Zealand Journal of Botany. SIR Publishing, Wellington, New Zealand.

LELLINGER, D. B. \& W. C. TAYLOR. 1997. A classification of spore ornamentation in the Pteridophyta. In JOHNS, R. J. (ed.), Holttum Memorial Volume, 33-42. Royal Bot. Gardens, Kew.

LUGARDON, B. 1969. Sur la structure fine des parois sporales d'Equisetum maximum Lamk. Pollen et Spores 11: 449-474.

MORBELLI, M. A. 1976. Estudio palinológico de las especies austrosudamericanas del género Blechnum L. subgénero Blechnum (Blechnaceae-Pteridophyta). Bol. Soc. Argent. Bot. Bol. 17: 155-175.
MORBELLI, M. A. 1980. Morfología de las esporas de Pteridophyta presentes en la región Fuegopatagónica, República Argentina. Opera Lilloana 28.

MORBELLI, M. A., M. R. PIÑEIRO \& G. E. GIUDICE. 2010. Spore morphology and wall ultrastructure of Hymenophyllaceae Link (Pteridophyta) from northwest Argentina. Grana 49: 37-46.

PONCE, M. M. \& E. R. de la SOTA. 2008. Equisetaceae. En: Zuloaga F., O Morrone \& M. Belgrano (eds.), Catálogo de las plantas vasculares del Cono Sur. Monogr. Syst. Bot. Missouri Bot. Gard. 107: 1-161. Missouri Bot. garden, Saint Louis.

PUNT, W., P. P. HOEN, S. BLACKMORE, S. NILSSON \& A. LE THOMAS. 2007. Glossary of pollen and spore terminology. Rev. 2nd ed. Rev. Palaeobot. Palynol. 143:1-81.

RINCÓN BARÓN, E. J., H. G. FORERO BALLESTEROS, L. V. GÉLVEZ LANDAZÁBAL, G. A. TORRES \& C. H. ROLLERI. 2011. Ontogenia de los estróbilos, desarrollo de los esporangios y esporogénesis de Equisetum giganteum (Equisetaceae) en los Andes de Colombia. Revista Biol. Trop. 59: 1845-1858.

ROWLEY, J. \& J. NILSSON. 1972. Structural stabilisation for electron microscopy of pollen from herbarium specimens. Grana 12: 23-30.

SOTA, E. R., de la. 1977. Pteridophyta. En: Cabrera, A. L. (ed.), Flora de la Provincia de Jujuy, Tomo 13 (2): 14-275. Colección Científica del INTA, Buenos Aires.

SPURR, A. R. 1969. A low-viscosity epoxi resin embedding medium for electron microscopy. $J$. Ultrastr. Res. 26: 31-43.

TRYON, A. F. \& B. LUGARDON. 1991. Spores of the Pteridophyta, Surface, wall structure and diversity based on electron microscope studies. SpringerVerlag, New York.

TRYON, R. M. \& A. F. TRYON. 1982. Ferns and allied plants. Springer-Verlag, New York.

WAGNER, W. H. 1974. Structure of spores in relation to fern phylogeny. Ann. Missouri Bot. Gard. 61: 332-353.

Recibido el 11 de noviembre de 2012, aceptado el 8 de noviembre de 2013 . 